\title{
Morfofisiologia e anatomia foliar de mudas micropropagadas e aclimatizadas de abacaxizeiro cv. Smooth Cayenne em diferentes substratos
}

\author{
Adriano Bortolotti da Silva ${ }^{1}$, Moacir Pasqual ${ }^{2}$, Aparecida Gomes de Araujo ${ }^{3}$, Francyane Tavares Braga 4 , \\ Evaristo Mauro de Castro ${ }^{2}$, Lúcia Helena de Barros Albert ${ }^{2}$
}

\section{RESUMO}

Objetivou-se com este trabalho determinar o melhor substrato e o tempo ideal de aclimatização em plantas de abacaxizeiro cv. Smooth Cayenne e comparar anatomicamente plântulas in vitro e aclimatizadas. Gemas foram inoculadas em meio MS + 6,66 $\mu \mathrm{M}$ de BAP e, após três subcultivos, as brotações foram transferidas para meio MS, por 30 dias. Os meios foram solidificados com $0,7 \%$ de ágar e tiveram seu $\mathrm{pH}$ ajustado para 5,8 antes da autoclavagem $\left(120^{\circ} \mathrm{C}\right.$ por 20 minutos). A incubação foi em sala de crescimento $\left(25 \pm 1^{\circ} \mathrm{C}\right.$, irradiância de $35 \mu \mathrm{mol} \mathrm{m} \mathrm{m}^{-2} \mathrm{~s}^{-1}$ e fotoperíodo de $\left.16 \mathrm{~h}\right)$. Os brotos obtidos in vitro foram transplantados para tubetes, em casa de vegetação, contendo os seguintes substratos: T1- Plantmax ${ }^{\circledR}+$ húmus, T2- Plantmax ${ }^{\circledR}+$ vermiculita e T3- Plantmax ${ }^{\circledR}$. Cortes anatômicos foram efetuados em folhas de propágulos mantidos in vitro e em plantas com 20, 40 e 60 dias de aclimatização nos diferentes substratos. A utilização do substrato Plantmax ${ }^{\circledR}+$ húmus na aclimatização propiciou maior desenvolvimento das mudas micropropagadas. A partir de 40 dias da aclimatização, as plantas apresentaram características anatômicas que podem favorecer a sua adaptação às condições de campo.

Palavras-chave: Bromeliaceae, Ananas comosus (L.) Merr., cultura de tecidos, aclimatização.

\section{ABSTRACT}

\section{Morphophysiology and leaf anatomy of plantlets of pineapple cv. Smoth Cayenne acclimatized in different substrates}

This study aimed to determine the optimal substrate and ideal time for acclimatization in plants of the 'Smooth Cayenne' pineapple and compare anatomically plantlets cultivated in vitro with acclimatized plants. Shoots were inoculated on MS with BAP $(6.66 \mu \mathrm{M})$. After three subcultures, the buds were transferred to MS medium for 30 days. The media were solidified with $0.7 \%$ agar, and the $\mathrm{pH}$ adjusted to 5.8 before autoclaving $\left(120^{\circ} \mathrm{C}\right.$ for 20 minutes $)$. Cultures were kept in a growth room $\left(25 \pm 1^{\circ} \mathrm{C}\right.$, irradiance of $35 \mathrm{ì} \mathrm{mol} \mathrm{m-}{ }^{2} \mathrm{~s}^{-1}$ and 16 hours photoperiod). The shoots obtained in vitro were transplanted into plastic pots in a greenhouse, containing the following substrates: T1- Plantmax ${ }^{\circ}+$ húmus $(\mathrm{P}+\mathrm{H})$, T2-Plantmax ${ }^{\circledR}+$ vermiculite $(\mathrm{P}+\mathrm{V})$ and T3-Plantmax ${ }^{\circledR}(\mathrm{P})$. Anatomical cuts were made on leaves of plants maintained in vitro and plants with 20, 40 and 60 days of acclimatization on different substrates. The use of Plantmax ${ }^{\circledR}$ + húmus substrate provided greater development in the acclimatization of plants. From 40 days of acclimatization, the plants showed anatomical features that may facilitate the adaptation to field conditions.

Key words: Bromeliaceae, Ananas comosus (L.) Merr., tissue culture, acclimatization.

Recebido para publicação em 20/07/2011 e aprovado em 25/09/2012.

'Engenheiro-Agrônomo, Doutor. Instituto de Ciências Agrárias, Universidade José do Rosário Vellano, Rodovia MG 179, Km 0, 37130-000, Alfenas, Minas Gerais, Brasil. bortolot@bol.com.br

${ }^{2}$ Engenheiros-Agrônomos, Doutores. Departamento de Agricultura, Universidade Federal de Lavras (UFLA), Caixa Postal 3037, 37200-000, Lavras, Minas Gerais, Brasil. mpasqual@dag.ufla.br; emcastro@dbi.ufla.br; lgcastro@dae.ufla.br

${ }^{3}$ Engenheira-Agrônoma, Doutora. Syngenta Seeds Ltda, Rodovia BR 452, Km 142, Caixa Postal 585, 38405-232, Uberlândia, Minas Gerais, Brasil. agaraujo2003@hotmail.com ${ }^{4}$ Bióloga, Doutora. Departamento de Biologia, Universidade do Estado da Bahia, Campus Paulo Afonso, Rua do Bom Conselho, 179, Alves de Souza, 48608-240, Paulo Afonso, Bahia, Brasil. bragaft@gmail.com 


\section{INTRODUÇÃO}

O abacaxi (Ananas comosus (L.) Merr.) é uma das fruteiras tropicais mais produzidas no mundo, ficando atrás somente da banana e dos citros. O Brasil está entre os sete maiores produtores mundiais de abacaxi e sua produção está concentrada principalmente nas regiões Nordeste, Sudeste e Norte, sendo os Estados da Paraíba, do Pará, de Minas Gerais, da Bahia, do Rio de Janeiro, Rio Grande do Norte e de São Paulo, respectivamente, os maiores produtores (IBGE, 2012).

$\mathrm{O}$ abacaxizeiro Smooth Cayenne apresenta grande importância econômica para os estados do Sudeste, principalmente São Paulo e Minas Gerais (Spironello, 2010), por atender às necessidades da indústria: consistência firme, formato cilíndrico (o que facilita o enlatamento), coloração intensa e sabor mais ácido (Savitci et al., 1996).

A cultura de tecidos é uma técnica de grande importância para o abacaxizeiro, pois proporciona a produção de milhares de mudas a partir de uma única gema, em pequeno intervalo de tempo e espaço, e totalmente livres de pragas e doenças. Um dos maiores obstáculos para a aplicação prática dessa técnica é a dificuldade de transferir com sucesso mudas da condição in vitro para ex vitro, devido à grande diferença entre as duas condições ambientes (Hazarika, 2006). Isso pode ser um fator limitante, devido à morte das plantas, ocasionada principalmente pela perda excessiva de água, e à mudança de metabolismo heterotrófico para autotrófico (Barboza et al., 2006).

Plantas cultivadas in vitro necessitam de um período de aclimatização em razão de alterações fisiológicas e anatômicas (morfologia foliar), que podem influenciar processos associados principalmente à fotossíntese e às trocas gasosas (Costa et al., 2009). Durante a aclimatização é imprescindível a escolha de um substrato adequado, o qual atenda às necessidades das mudas e que permita o menor número possível de perdas e melhor adaptação das plantas ao mecanismo autotrófico.

Neste contexto, otimizar a propagação in vitro do abacaxizeiro e realizar estudos anatômicos dos tecidos são fundamentais para o sucesso da produção de mudas por cultura de tecidos. Assim, os objetivos deste trabalho foram determinar o melhor substrato, bem como o tempo ideal de aclimatização em plantas de abacaxizeiro cv. Smooth Cayenne, com base nos estudos morfofisiológicos, e realizar estudos anatômicos em propágulos in vitro e aclimatizados.

\section{MATERIAL E MÉTODOS}

O material vegetal foi estabelecido a partir de gemas axilares de plantas adultas de abacaxizeiro cultivar Smooth Cayenne, mantidas no Banco de Germoplasma do Setor de Fruticultura do Departamento de Agricultura da Uni- versidade Federal de Lavras (DAG/UFLA). As gemas foram desinfestadas em solução de álcool $70 \%$ por 1 min, hipoclorito de sódio $1 \%$ por 20 min e posteriormente lavadas em água destilada e autoclavada, por três vezes. Após esse procedimento, as gemas foram inoculadas em tubos de ensaio contendo $10 \mathrm{~mL}$ de meio. O meio de cultura foi composto pelos sais do MS (Murashige \& Skoog, 1962), contendo 6,66 $\mu \mathrm{M}$ de BAP (6-benzilaminopurina) e $30 \mathrm{~g} \mathrm{~L}^{-1}$ de sacarose, seguindo metodologia descrita por Silva (2006). Todos os meios foram solidificados com $0,7 \%$ de ágar e tiveram seu pH ajustado em 5,8 antes da autoclavagem a $120^{\circ} \mathrm{C}, 1,1$ atm durante $20 \mathrm{~min}$.

Ao final do processo de estabelecimento (Figura 1A), das 32 gemas inoculadas somente seis conseguiram se diferenciar em novos brotos. As brotações obtidas entraram na fase de multiplicação (Figura $1 \mathrm{~B}$ ), sendo inoculadas em frascos com capacidade de $250 \mathrm{~mL}$, contendo 30 $\mathrm{mL}$ de meio de cultura e realizados três subcultivos (espaçados de três meses), em meio de cultura semelhante ao descrito anteriormente e apresentando em média 16 brotos/explante de taxa de multiplicação. $\mathrm{Na}$ fase de enraizamento (Figura 1C), os brotos, obtidos na fase anterior, foram inoculados em $30 \mathrm{~mL}$ de meio, sendo mantidos por 30 dias em meio MS sem reguladores de crescimento para enraizamento, uniformização e eliminação do efeito residual da citocinina, antes da instalação do experimento.

Em todas as fases, após a inoculação, os tubos de ensaio ou os frascos foram incubados em sala de crescimento a $25 \pm 1^{\circ} \mathrm{C}$ de temperatura, irradiância de $36 \mu \mathrm{mol} \mathrm{m}{ }^{-2} \mathrm{~s}^{-1} \mathrm{e}$ fotoperíodo de $16 \mathrm{~h}$. Após o processo de enraizamento, os brotos foram retirados dos frascos, lavados em água destilada para remover o excesso de meio de cultura no sistema radicular, selecionados com base no tamanho (aproximadamente 1,5 cm) e transplantados (Figura 1D) para tubetes contendo os seguintes substratos: Plantmax ${ }^{\circledR}$ + húmus $(\mathrm{P}+\mathrm{H})$, Plantmax ${ }^{\circledR}+\operatorname{vermiculita}(\mathrm{P}+\mathrm{V})$ e Plantmax ${ }^{\circledR}$ (P). Os tubetes foram mantidos em casa de vegetação sob sombrite ${ }^{\circledR} 50 \%$, sistema de nebulização intermitente e ventilação forçada.

Após esse período, as plantas foram avaliadas em relação à altura das plantas (ALT) e ao comprimento da raiz (CR), com auxílio de régua; número de folhas (NF) por plântula, por meio de contagem; e massas de matérias secas da parte aérea (MSPA) e do sistema radicular (MSR). As massas de matérias secas foram medidas após a secagem em estufa com ventilação forçada, por 10 dias, a $70^{\circ} \mathrm{C}$.

$\mathrm{O}$ delineamento experimental utilizado foi o inteiramente casualizado, com três tratamentos e três repetições, sendo cada repetição composta por quatro plantas.

Para o estudo anatômico foi padronizado para todos os tratamentos o emprego de seções do terço mediano de folhas completamente expandidas de plântulas mantidas 
in vitro, em meio MS, e de plantas com 20, 40 e 60 dias de aclimatização em casa de vegetação, cultivadas em diferentes substratos.

As folhas foram estocadas em álcool etílico $70 \%$ (v/v). Os cortes anatômicos foram efetuados a mão livre. Posteriormente, sucedeu-se a clarificação em solução de hipoclorito de sódio 20\% (v/v do produto comercial), por um período de $5 \mathrm{~min}$, e três lavagens em água destilada. Em seguida, o material foi neutralizado com solução de ácido acético $1 \%(\mathrm{v} / \mathrm{v})$ por $1 \mathrm{~min}$, repetindo-se a lavagem em água destilada. Para a avaliação dos tecidos foliares (medições de espessura das superfícies adaxial e abaxial da epiderme e dos parênquimas aquífero e clorofiliano) foram realizados cortes transversais, os quais foram corados com azul de astra-safranina (astrablau $0,1 \%$ e safranina $1 \%$ na proporção de 7:3). A partir das secções transversais foram efetuadas três medições em cada planta, no total de cinco plantas, com auxílio da ocular micrométrica.

Para as avaliações relativas à caracterização dos estômatos (número médio por $\mathrm{mm}^{2}$ e diâmetros polar e equatorial) foram realizados cortes paradérmicos na região mediana das folhas, os quais foram colocados sobre uma lâmina contendo safranina a $1 \%$ e água glicerinada (na proporção 1:1) e realizada lutagem com esmalte. Posteriormente, essas lâminas foram fotomicrografadas utilizando-se uma máquina fotográfica acoplada em microscópio Olympus $\mathrm{CBB}^{\circledR}$ (Olympus Co, Tokyo, Japan) de câmara clara. As medições anatômicas foram analisadas utilizando-se delineamento inteiramente casualizado (DIC), em fatorial $3 \times 3$, sendo três substratos e três tempos de aclimatização, com cinco repetições.

Os resultados do melhor substrato para a aclimatização de plantas, do experimento anteriormente citado, foram comparados com aqueles obtidos a partir de plântulas cultivadas in vitro. Este experimento foi realizado em DIC, sendo conduzido em quatro tratamentos: plântulas in vitro e plantas cultivadas em P + H aos 20, 40 e 60 dias de aclimatização.

Os dados de todos os experimentos foram submetidos à análise e as médias, agrupadas com o teste de Scott-Knott, do programa Sisvar (Ferreira, 2011), a 5\% de probabilidade.
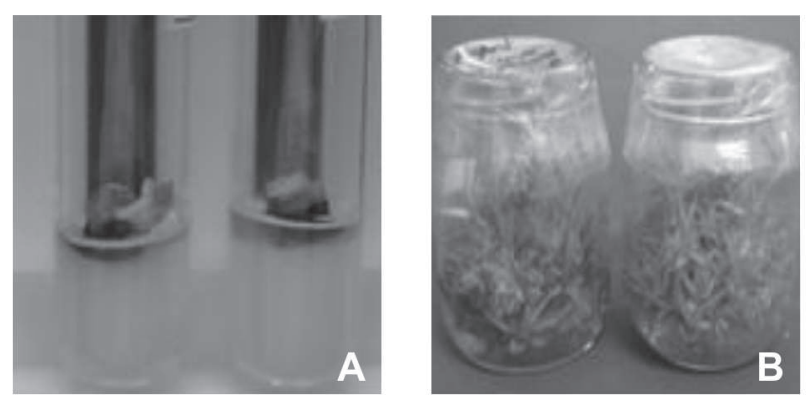

\section{RESULTADOS E DISCUSSÃO}

\section{Características fitotécnicas}

Houve diferenças significativas entre os substratos utilizados para todas as variáveis estudadas. Maior altura da parte aérea foi registrada em plantas que permaneceram 180 dias em substrato Plantmax ${ }^{\circledR}$ adicionado de húmus ou vermiculita, diferindo significativamente do tratamento em que os propágulos permaneceram apenas no Plantmax ${ }^{\circledR}$ (Tabela 1). Respostas similares foram obtidas por Souza-Júnior et al. (2001), que observaram maior crescimento de propágulos de abacaxizeiro cv. Pérola em substratos que continham material orgânico e resultados inferiores no substrato composto apenas por Plantmax®. Resultados semelhantes também foram obtidos por Calvete et al. (2000) ao concluírem que os substratos que apresentam maior retenção de água proporcionam maior crescimento de mudas de morangueiro. Souza-Júnior et al. (2001) também citaram que o substrato de transplantio deve ter boa capacidade de retenção de umidade e não compactar excessivamente, comprometendo a drenagem e a aeração radicular.

O substrato Plantmax ${ }^{\circledR}$ + húmus também proporcionou maior crescimento de plantas de figueira Roxo de Valinhos na fase de aclimatização, provavelmente pela maior quantidade de nutrientes existentes no meio fornecido na fase inicial de crescimento e desenvolvimento (Fráguas, 2003). O mesmo autor observou também redução no crescimento após 60 dias da aclimatização, devido à compactação do substrato, dificultando a absorção de água e nutrientes, uma vez que as plantas, por apresentarem maior tamanho, necessitam de maior quantidade de nutrientes e água.

Obteve-se maior número de folhas no substrato contendo húmus, superando significativamente os outros dois tratamentos (Tabela 1), concordando com afirmações de Moreira et al. (2007) de que o substrato deve apresentar, entre outras características, elevado espaço de aeração, permitindo perfeito crescimento e desenvolvimento do sistema radicular e, consequentemente, da parte aérea da planta. O número de folhas constitui-se um dos principais
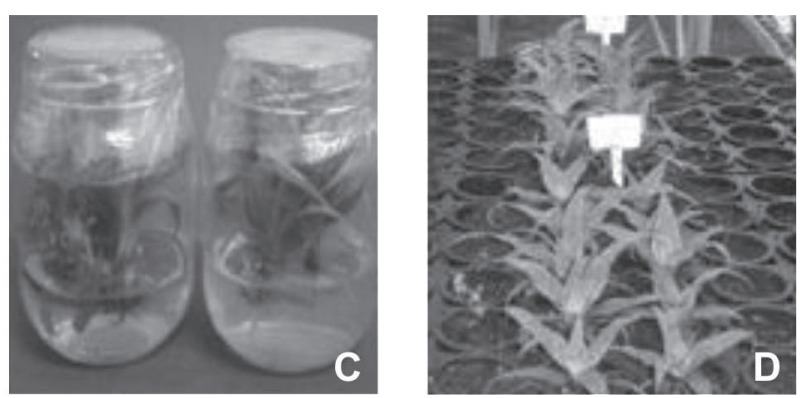

Figura 1. Fases da propagação in vitro do abacaxizeiro cv. Smooth Cayenne: A - Estabelecimento das gemas; B - Fase de multiplicação; C - Fase de enraizamento; e D - Aclimatização de plantas.

Rev. Ceres, Viçosa, v. 59, n.5, p. 580-586, set/out, 2012 
fatores no índice de pegamento de mudas em campo, uma vez que é responsável pela captação de energia solar e produção de matéria orgânica por meio da fotossíntese.

O melhor resultado para massa de matéria seca da parte aérea (MSPA) foi obtido em plantas cultivadas com $\mathrm{P}+\mathrm{H}$ (Tabela 1). Pode-se inferir que, além da melhoria nos aspectos nutricionais do substrato, o húmus confere também melhor propriedade física, a ponto de melhorar o suprimento da planta em água e nutrientes (Souza-Júnior et al., 2001).

Para massa de matéria seca do sistema radicular (MSR), o substrato Plantmax ${ }^{\circledR}$ apresentou respostas inferiores à dos demais tratamentos (Tabela 1). Ao contrário, Fráguas (2003), na aclimatização de figueira, registrou que o uso de Plantmax ${ }^{\circledR}$ resultou em maiores massas de matérias secas, tanto da parte aérea como do sistema radicular. Collard et al. (2004), estudando diferentes substratos na aclimatização de mudas de abacaxizeiro, constataram aumento da altura de $47,2 \%$ e massa de matéria seca de $66 \%$ para o substrato Plantmax® em relação ao solo suplementado com material orgânico. Diante do exposto, percebe-se que as respostas variam entre espécies e cultivares.

No presente trabalho, o comprimento da raiz foi maior no substrato $\mathrm{P}+\mathrm{H}$, seguido do tratamento $\mathrm{P}+\mathrm{V}$ (Tabela 1). Apesar das mudas de abacaxizeiro micropropagadas serem de fácil enraizamento, é importante observar o desenvolvimento das raízes durante a aclimatização, visto que, segundo Hazarika (2006), raízes formadas in vitro podem se apresentar pouco ramificadas, quebradiças, e até com inadequada conexão vascular.

\section{Anatomia foliar}

A partir das secções transversais das folhas de propágulos de abacaxizeiro cultivadas in vitro e aclimatizadas em casa de vegetação, observou-se que o limbo foliar apresentou epiderme unisseriada nas duas superfícies, hipoestomática e mesofilo dorsiventral, com presença de parênquima aquífero, voltada para a face adaxial, e parênquima clorofiliano voltado para a face abaxial (Figura 2). Em cortes paradérmicos na superfície inferior da epiderme, observaram-se estômatos do tipo tetracítico envolvido por quatro células subsidiárias, duas delas paralelas às células-guarda, sendo o par restante polar e frequentemente menor (Figura 3).
Houve diferença significativa dos tratamentos para todas as características anatômicas estudadas, exceto diâmetros polar e equatorial (Tabela 2). Maior espessura da superfície adaxial da epiderme foi constatada quando as plantas foram cultivadas em Plantmax ${ }^{\circledR}$, independentemente do tempo de aclimatização (Tabela 2). Verificou-se que aos 20 dias de aclimatização não houve diferença estatística na espessura da superfície abaxial da epiderme em relação aos tratamentos $\mathrm{P}+\mathrm{H}$ e $\mathrm{P}+\mathrm{V}$. Aos 40 e 60 dias de aclimatização, a maior espessura da superfície abaxial da epiderme foi registrada com o Plantmax ${ }^{\circledR}$, resultado semelhante ao da superfície adaxial (Tabela 2) nos mesmos períodos.

Maior espessura da epiderme confere à planta cultivada in vitro maior possibilidade de sobrevivência durante a transferência para o ambiente ex vitro, o que é um fator importante para o sucesso da aclimatização (Barboza et al., 2006; Silva et al., 2008).

As mensurações das espessuras dos parênquimas aquífero (tecido de reserva) e clorofiliano apresentaram comportamento diferenciado em relação à epiderme. Aos 20 dias, o substrato que promoveu aumento inicial da espessura do parênquima aquífero foi o Plantmax ${ }^{\circledR}$ usado isoladamente; porém, a partir dos 40 dias, houve aumento significativo desse parênquima com uso do substrato P + $\mathrm{H}$, o qual se manteve até os 60 dias nesse mesmo substrato. Já o parênquima clorofiliano apresentou, nos primeiros 20 dias, maior espessura em substrato Plantmax ${ }^{\circledR}$ ou P + V. A partir dos 40 dias, o substrato $\mathrm{P}+\mathrm{H}$ foi o que favoreceu maior crescimento na espessura desse tecido até os 60 dias de cultivo (Tabela 2).

O aumento na espessura do mesofilo constitui padrão clássico de resposta ao ambiente de cultivo durante a aclimatização (alta intensidade de luz, alta temperatura e baixa umidade relativa do ar em relação à sala de crescimento) e evidencia a plasticidade adaptativa da espécie (Barboza et al., 2006; Braga et al., 2011).

$\mathrm{O}$ substrato que apresentou maior quantidade de estômatos foi o $\mathrm{P}+\mathrm{H}$, independentemente do período de dias de permanência das mudas em casa de vegetação (Tabela 2), sendo verificada aos 20 dias resposta similar para o substrato $\mathrm{P}+\mathrm{V}$. Alguns autores descrevem que, apesar de a variabilidade estomática ser um fenômeno re-

Tabela 1. Média e desvio padrão da altura (ALT), número de folhas (NF), massas de matérias secas da parte aérea (MSPA) e do sistema radicular (MSR) e comprimento da raiz (CR) de brotações de abacaxizeiro cv. Smooth Cayenne aclimatizadas em diferentes substratos

\begin{tabular}{lccccc}
\hline Tratamentos & ALT $(\mathbf{c m})$ & NF & MSPA $(\mathbf{g})$ & MSR $(\mathbf{g})$ & CR $(\mathbf{c m})$ \\
\hline $\mathrm{P}+\mathrm{H}$ & $14,83 \pm 0,83 \mathrm{a}$ & $20,55 \pm 1,71 \mathrm{a}$ & $1,43 \pm 0,11 \mathrm{a}$ & $0,20 \pm 0,01 \mathrm{a}$ & $19,89 \pm 0,38 \mathrm{a}$ \\
$\mathrm{P}+\mathrm{V}$ & $12,38 \pm 1,05 \mathrm{a}$ & $16,22 \pm 0,69 \mathrm{~b}$ & $0,91 \pm 0,16 \mathrm{~b}$ & $0,20 \pm 0,09 \mathrm{a}$ & $18,72 \pm 1,30 \mathrm{a}$ \\
$\mathrm{P}$ & $9,90 \pm 0,25 \mathrm{~b}$ & $15,11 \pm 0,84 \mathrm{~b}$ & $0,51 \pm 0,03 \mathrm{c}$ & $0,06 \pm 0,02 \mathrm{~b}$ & $8,75 \pm 0,58 \mathrm{~b}$ \\
\hline
\end{tabular}

Médias seguidas de mesma letra, na coluna, não diferem, significativamente, entre si pelo teste de Scott-Knott a 5\% de probabilidade. Plantmax $^{\circledR}(\mathrm{P})$, Vermiculita (V), e Húmus $(\mathrm{H})$. 
lacionado principalmente à umidade relativa dentro dos frascos, a intensidade luminosa pode ter implicações nesse processo (Dignart et al., 2009; Braga et al., 2009). Assim, de acordo com os resultados apresentados, pode-se notar maior número de estômatos em plantas que permaneceram mais tempo expostas ao sol (luz natural).

Os diâmetros equatorial e polar dos estômatos não apresentaram diferença significativa em relação aos diferentes substratos testados nos períodos de 40 e 60 dias de aclimatização (Tabela 2). Os estômatos são estruturas fundamentais para as plantas, pois através deles ocorrem os processos de troca gasosa. Portanto, qualquer variação em número e/ou tamanho desses pode acarretar maior ou menor eficiência da planta quanto à taxa fotossintética (Batagin et al., 2009).

\section{Comparação anatômica entre plântulas mantidas in vitro e aclimatizadas em substrato Plantmax ${ }^{\circledR}+$ húmus ao longo do tempo}

Ao comparar as características anatômicas de plântulas mantidas in vitro e mudas aclimatizadas em substrato

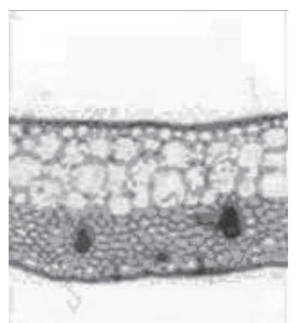

In Vitro
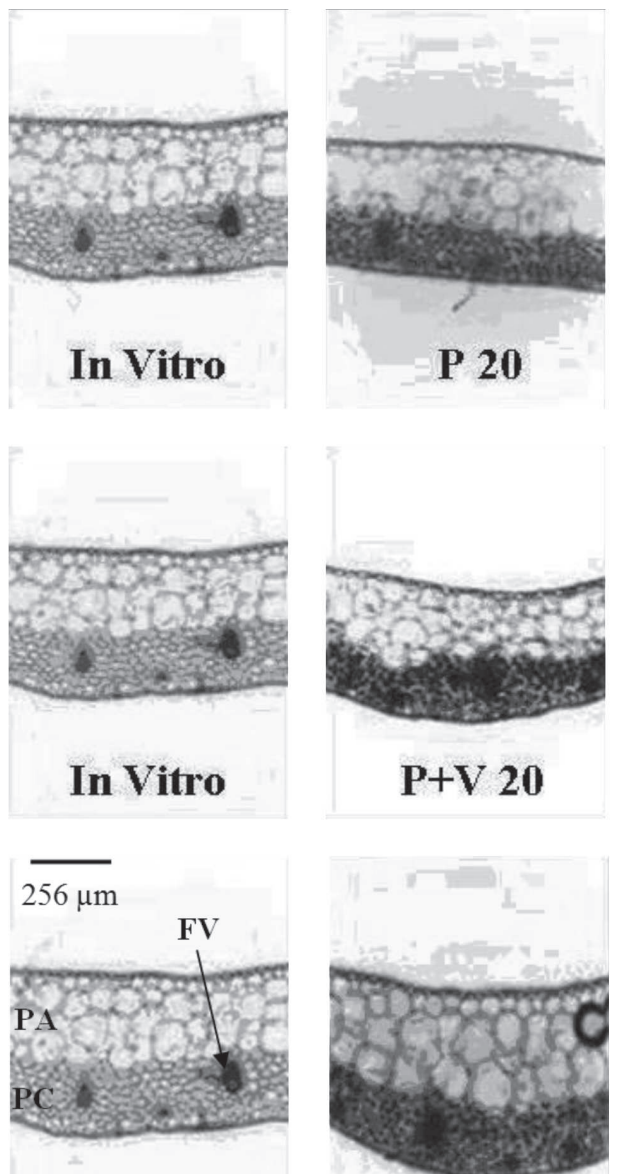

In Vitro

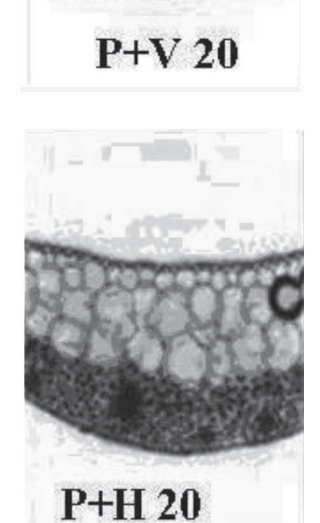

Plantmax ${ }^{\circledR}$ + húmus, observaram-se diferenças significativas ao longo do processo de aclimatização (Tabela 3 ).

As dimensões dos tecidos foliares e o número de estômatos foram influenciados pelos tratamentos. Além da organização anatômica dos tecidos foliares apresentarem diferenças, como forma e arranjo das células entre os propágulos in vitro e plantas aclimatizadas, a espessura das superfícies da epiderme (adaxial e abaxial), dos parênquimas clorofilianos e aquíferos das folhas de abacaxizeiro diferiram de forma significativa ao longo do tempo (Tabela 3 e Figura 2). Aos 40 dias de aclimatização, observou-se maior espessura na superfície superior (adaxial) da epiderme. A face inferior da epiderme ficou menos espessa nos propágulos in vitro e diferiram estatisticamente das mudas em fase de aclimatização (Tabela 3).

As folhas das plantas de abacaxizeiro formadas durante a aclimatização apresentaram camadas mais espessas dos parênquimas aquíferos e clorofilianos aos 60 e 40 dias da aclimatização, respectivamente (Figura 2 e Tabela 3). Além da diferença significativa nas espessuras do
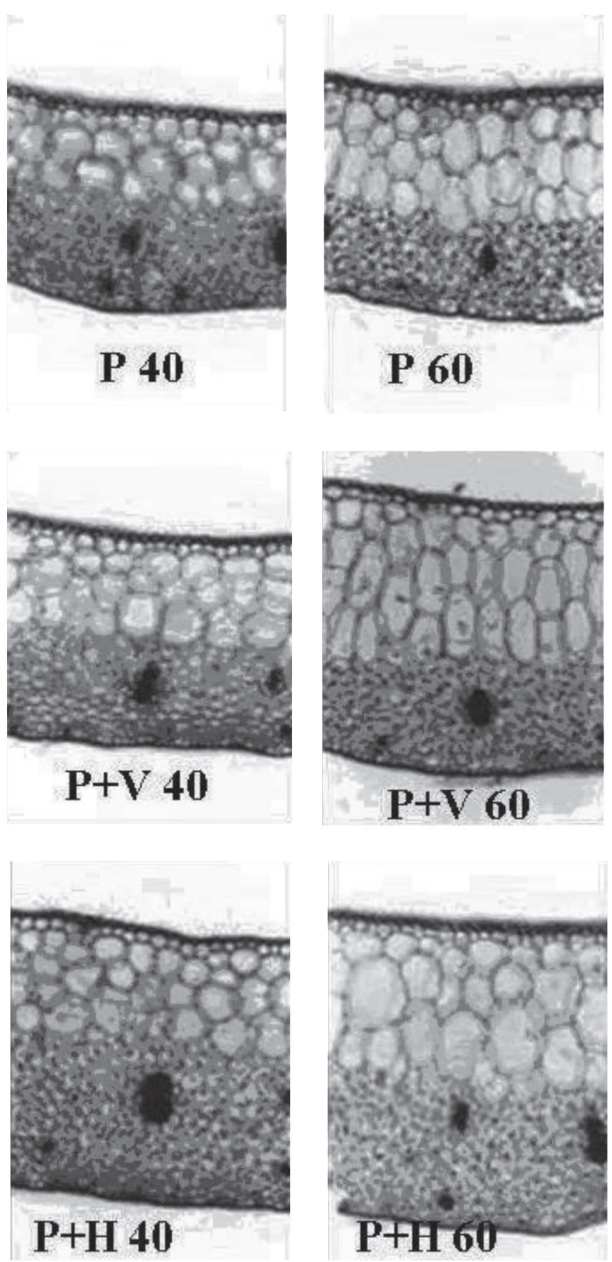

Figura 2. Fotomicrografias de secções transversais do terço mediano de folhas de propágulos de abacaxizeiro cv. Smooth Cayenne in vitro e cultivados em diferentes substratos aos 20,40 e 60 dias de aclimatização (objetiva de 10x). Substratos: Plantmax ${ }^{\circledR}$ (P), Vermiculita (V), e Húmus (H). Feixes vasculares (FV), Parênquima aquífero (PA), e Parênquima clorofiliano (PC). 
mesofilo das folhas de abacaxizeiro analisadas, percebeuse, igualmente, diferença no formato das células, demonstrando a sua plasticidade em razão do tratamento utilizado e das épocas de análise (Figura 2). Braga et al. (2011) registraram que plantas de abacaxizeiro Gomo de Mel com 60 dias de aclimatização em substrato vermiculita mostraram as maiores espessuras para todos os tecidos do limbo foliar.

Com relação aos estômatos, observaram-se estômatos do tipo tetracítico com aumento significativo no número desses por $\mathrm{mm}^{2}$ a partir dos 40 dias de aclimatização, porém não ocorrendo diferença em seu formato ao longo do período de adaptação das plantas. Barboza et al. (2006)

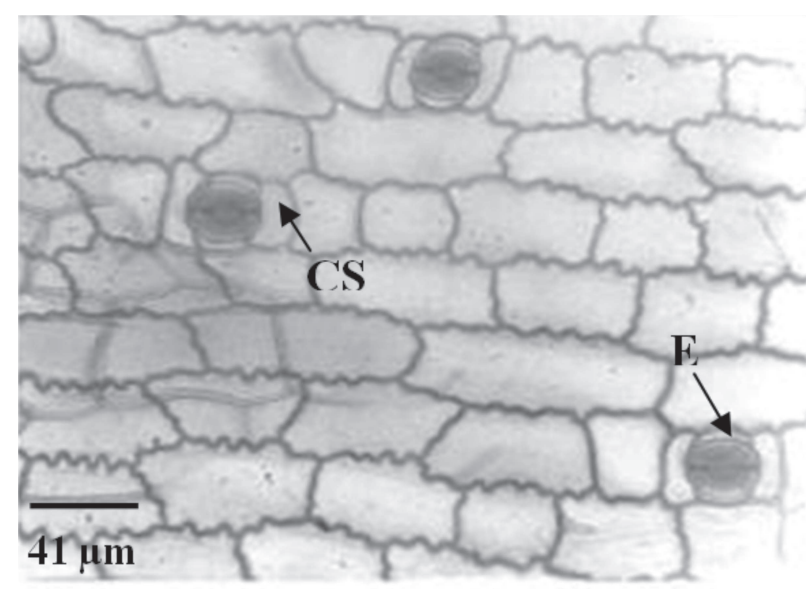

Figura 3. Fotomicrografia de secção paradérmica (objetiva de 40x) da face abaxial da epiderme de folhas de abacaxizeiro cv. Smooth Cayenne aos 60 dias de cultivo em substrato $(\mathrm{P}+\mathrm{H})$ apresentando estômato tetracítico (E) e quatro células subsidiárias (CS). Substratos: Plantmax ${ }^{\circledR}$ (P) e Húmus (H). verificaram que folhas de plantas in vitro apresentaram, em média, 54 estômatos $\mathrm{mm}^{-2}$, valor estatisticamente inferior ao observado em folhas de casa de vegetação, que foi de 62 estômatos $\mathrm{mm}^{-2}$. A frequência estomática constatada neste trabalho revela consonância com os ambientes estudados, tendo em vista que a baixa atividade autotrófica e baixa eficiência estomática, impostas pelas condições in vitro, estariam relacionadas com a diminuição do número de estômatos por unidade de área.

Os dados obtidos estão de acordo com aqueles encontrados por Barboza et al. (2006), os quais afirmaram que folhas de mudas de abacaxizeiro micropropagadas in vitro e em casa de vegetação apresentam estruturas básicas semelhantes; entretanto, variações estomáticas e alterações no espessamento da epiderme, formato e sinuosidade das células do mesofilo podem ser observadas nos diferentes ambientes de cultivo, demonstrando plasticidade fenotípica.

De acordo com a caracterização anatomicamente de plantas cultivadas em condições in vitro em comparação com plantas aclimatizadas, observou-se pouco espessamento da epiderme e do parênquima em mudas obtidas in vitro. Com relação ao número de estômatos, houve aumento desses ao longo da adaptação em casa de vegetação. Portanto, as anormalidades morfológicas e anatômicas ocorridas durante o cultivo in vitro podem ser reparadas com o período apropriado de aclimatização.

De modo geral, as plantas de abacaxizeiro Smooth Cayenne apresentaram grande plasticidade em relação aos diferentes substratos, tempos de aclimatização e ambientes de cultivo, alterando as características biométricas e a

Tabela 2. Média e desvio padrão da espessura média $(\mu \mathrm{m})$ dos tecidos adaxial (EAd) e abaxial (EAb) da epiderme, parênquima aquífero (PA), clorofiliano (PC), diâmetros polar (DP) e equatorial (DE) do estômato e número de estômatos (NE) em plantas de abacaxizeiro cv. Smooth Cayenne cultivadas em diferentes substratos aos 20, 40 e 60 dias de aclimatização

\begin{tabular}{|c|c|c|c|c|c|c|c|}
\hline \multicolumn{8}{|c|}{20 dias de aclimatização } \\
\hline Trat. & EAd & $\mathbf{E A b}$ & PA & $\mathbf{P C}$ & $\mathbf{N E}$ & DP & $\mathbf{D E}$ \\
\hline $\mathrm{P}+\mathrm{H}$ & $21,3 \pm 1,2 \mathrm{c}$ & $14,0 \pm 0,5 \mathrm{a}$ & $274,5 \pm 1,7 b$ & $184,7 \pm 2,5 b$ & $74,7 \pm 1,6 \mathrm{a}$ & $19,5 \pm 0,7 \mathrm{a}$ & $25,1 \pm 0,9 b$ \\
\hline $\mathrm{P}+\mathrm{V}$ & $30,1 \pm 0,7 \mathrm{~b}$ & $13,8 \pm 0,3 \mathrm{a}$ & $274,5 \pm 0,5 b$ & $229,2 \pm 0,5 \mathrm{a}$ & $76,9 \pm 3,6 \mathrm{a}$ & $19,2 \pm 0,7 \mathrm{a}$ & $25,9 \pm 0,9 b$ \\
\hline $\mathrm{P}$ & $35,3 \pm 0,3 \mathrm{a}$ & $12,5 \pm 0,4 b$ & $306,9 \pm 0,19 a$ & $217,3 \pm 1,6 a$ & $64,4 \pm 2,0 b$ & $19,5 \pm 1,06 a$ & $28,6 \pm 1,3 a$ \\
\hline \multicolumn{8}{|c|}{40 dias de aclimatização } \\
\hline Trat. & EAd & EAb & PA & PC & $\mathbf{N E}$ & DP & $\mathbf{D E}$ \\
\hline $\mathrm{P}+\mathrm{H}$ & $31,3 \pm 0,5 b$ & $12,7 \pm 0,4 \mathrm{c}$ & $421,4 \pm 6,3 \mathrm{a}$ & $424,3 \pm 1,3 \mathrm{a}$ & $108,8 \pm 3,3 a$ & $19,6 \pm 0,5 \mathrm{a}$ & $24,5 \pm 1,8 \mathrm{a}$ \\
\hline $\mathrm{P}+\mathrm{V}$ & $29,7 \pm 0,6 c$ & $16,9 \pm 0,3 b$ & $270,8 \pm 2,6 b$ & $267,3 \pm 2,4 b$ & $90,2 \pm 2,2 b$ & $19,9 \pm 0,3 \mathrm{a}$ & $24,5 \pm 0,6 \mathrm{a}$ \\
\hline $\mathrm{P}$ & $48,7 \pm 0,7 \mathrm{a}$ & $32,3 \pm 0,6 \mathrm{a}$ & $251,0 \pm 0,8 \mathrm{c}$ & $396,6 \pm 6,3 \mathrm{a}$ & $81,3 \pm 4,6 \mathrm{c}$ & $19,0 \pm 1,2 \mathrm{a}$ & $24,3 \pm 1,9 \mathrm{a}$ \\
\hline \multicolumn{8}{|c|}{60 dias de aclimatização } \\
\hline Trat. & EAd & $\mathbf{E A b}$ & $\mathbf{P A}$ & PC & $\mathbf{N E}$ & DP & DE \\
\hline $\mathrm{P}+\mathrm{H}$ & $28,5 \pm 0,8 \mathrm{c}$ & $13,7 \pm 0,4 \mathrm{c}$ & $435,5 \pm 2,7 \mathrm{a}$ & $411,9 \pm 0,4 a$ & $108,0 \pm 4,8 \mathrm{a}$ & $19,5 \pm 1,2 \mathrm{a}$ & $23,1 \pm 0,5 \mathrm{a}$ \\
\hline $\mathrm{P}+\mathrm{V}$ & $37,6 \pm 0,4 b$ & $20,2 \pm 0,5 b$ & $307,6 \pm 0,7 b$ & $369,9 \pm 1,3 b$ & $89,5 \pm 1,3 b$ & $19,1 \pm 3,1 \mathrm{a}$ & $25,5 \pm 0,5 \mathrm{a}$ \\
\hline $\mathrm{P}$ & $39,4 \pm 0,46 \mathrm{a}$ & $22,0 \pm 0,6 \mathrm{a}$ & $289,4 \pm 1,19 \mathrm{c}$ & $277,7 \pm 4,1 \mathrm{c}$ & $89,4 \pm 5,0 \mathrm{~b}$ & $19,8 \pm 0,9 \mathrm{a}$ & $23,8 \pm 1,7 \mathrm{a}$ \\
\hline
\end{tabular}

Médias seguidas de mesma letra, na coluna, não diferem, significativamente, entre si pelo teste de Scott-Knott a $5 \%$ de probabilidade. Tratamento (Trat.), Plantmax ${ }^{\circledR}$ (P), Vermiculita (V), e Húmus (H). 
Tabela 3. Média e desvio padrão da espessura média $(\mu \mathrm{m})$ dos tecidos epidérmicos adaxial (EAd) e abaxial (EAb), parênquima aquífero (PA), clorofiliano (PC) e número de estômatos (NE) em plantas de abacaxizeiro cv. Smooth Cayenne cultivadas in vitro e em Plantmax ${ }^{\circledR}+$ húmus $(\mathrm{P}+\mathrm{H})$ aos 20, 40 e 60 dias de aclimatização

\begin{tabular}{lccccc}
\hline Tratamentos & EAd & EAb & PA & PC & NE \\
\hline In vitro & $15,4 \pm 1,6 \mathrm{~d}$ & $11,3 \pm 1,4 \mathrm{~b}$ & $209,4 \pm 2,3 \mathrm{~d}$ & $182,6 \pm 1,4 \mathrm{c}$ & $71,0 \pm 6,6 \mathrm{~b}$ \\
$\mathrm{P}+\mathrm{H}(20$ dias $)$ & $21,3 \pm 1,2 \mathrm{c}$ & $14,0 \pm 0,5 \mathrm{a}$ & $274,5 \pm 1,7 \mathrm{c}$ & $184,7 \pm 2,5 \mathrm{c}$ & $74,7 \pm 1,6 \mathrm{~b}$ \\
$\mathrm{P}+\mathrm{H}(40$ dias $)$ & $31,3 \pm 0,5 \mathrm{a}$ & $12,7 \pm 0,4 \mathrm{a}$ & $421,4 \pm 6,3 \mathrm{~b}$ & $424,3 \pm 1,3 \mathrm{a}$ & $108,8 \pm 3,3 \mathrm{a}$ \\
$\mathrm{P}+\mathrm{H}$ (60 dias) & $28,5 \pm 0,8 \mathrm{~b}$ & $13,7 \pm 0,4 \mathrm{a}$ & $435,5 \pm 2,7 \mathrm{a}$ & $411,9 \pm 0,4 \mathrm{~b}$ & $108,0 \pm 4,8 \mathrm{a}$ \\
\hline
\end{tabular}

Médias seguidas de mesma letra, na coluna, não diferem, significativamente, entre si pelo teste de Scott-Knott a $5 \%$ de probabilidade

anatomia foliar das plantas (diferenciação dos tecidos). Essas modificações, ao longo da aclimatização, estão direta e positivamente relacionadas com a taxa fotossintética e a transpiração, favorecendo, assim, melhor desenvolvimento das mudas em casa de vegetação e melhor adaptação dessas em condições de campo.

\section{CONCLUSÕES}

A utilização do substrato P + H (Plantmax ${ }^{\circledR}$ + húmus) na aclimatização propiciou maior desenvolvimento de plântulas micropropagadas de abacaxizeiro cv. Smooth Cayenne.

A partir de 40 dias da aclimatização, as plantas apresentam características anatômicas que podem favorecer a adaptação delas às condições de campo.

\section{REFERÊNCIAS}

Barboza SBSC, Graciano-Ribeiro D, Teixeira JB, Portes TA \& Souza LAC (2006) Anatomia foliar de plantas micropropagadas de abacaxi. Pesquisa Agropecuária Brasileira, 41:185-194.

Batagin KD, Almeida CV, Tanaka FAO \& Almeida M (2009) Alterações morfológicas foliares em abacaxizeiro cv. IAC Gomo de Mel micropropagados e aclimatizados em diferentes condições luminosas. Acta Botânica Brasílica, 23:85-92.

Braga FT, Nunes CF, Favero AC, Pasqual M, Carvalho JG \& Castro EM (2009) Características anatômicas de mudas de morangueiro micropropagadas com diferentes fontes de silício. Pesquisa Agropecuária Brasileira, 44:128-132.

Braga FT, Pasqual M, Castro EM \& Rafael GC (2011) Características morfofisiológicas de abacaxizeiro 'gomo de mel' enraizado in vitro sob luz natural e substrato vermiculita. Revista Brasileira de Fruticultura, 33:551-557.

Calvete EO, Kämpf NA \& Daudt R (2000) Efeito do substrato na aclimatização ex vitro de morangueiro cv. Campinas, Fragaria $\mathrm{x}$ ananassa Duch. In: Kämpf NA \& Fermino MH (Eds) Substrato para plantas - a base da produção vegetal em recipientes. Porto Alegre, Genesis. p.257-264.

Collard FH, Almeida A \& Costa MCR (2004) Obtenção de mudas de abacaxi da variedade Smooth Cayenne (Ananas comosus L.) a partir do seccionamento transversal circular do caule submetido a diferentes substratos. Disponível em: <www.unitau.br/ prppg/inicient/veic/tabela_resumos_bio.htm)>. Acessado em: 23 de abril de 2010

Costa FHS, Pereira JES, Pasqual M, Castro EM \& Santos AM (2009) Perda de água e modificações anatômicas em folhas de plantas de bananeiras micropropagadas durante a aclimatização. Revista Ciência Rural, 39:742-748.
Dignart SL, Castro EM, Pasqual M, Ferronato A, Braga FT \& Paiva R (2009) Luz natural e concentrações de sacarose no cultivo in vitro de Cattleya walkeriana. Ciência e Agrotecnologia, 33:780-787.

Ferreira DF (2011) Sisvar: A computer statistical analysis system. Ciência e Agrotecnologia, 35:1039-1042.

Fráguas CB (2003) Micropropagação e aspectos da anatomia foliar da figueira 'Roxo de Valinhos'. Dissertação de Mestrado. Universidade Federal de Lavras, Lavras. 110p.

Hazarika BN (2006) Morphophysiological disorders in vitro culture of plants. Scientia Horticulturae, 108:105-120.

IBGE - Instituto Brasileiro de Geografia e Estatística (2012) Levantamento sistemático da produção agrícola. Disponível em: <http://www.ibge.gov.br/home/estatistica/indicadores/ agropecuaria/lspa/lspa_201202.pdf >. Acessado em: 28 de maio de 2012.

Moreira MA, Carvalho JG, Fráguas CB \& Pasqual M (2007) Respostas à adubação NPK de mudas micropropagadas de abacaxizeiro cv. Pérola em fase de aclimatização. Plant Cell, Culture and Micropropagation, 3:17-22.

Murashige T \& Skoog F (1962) A revised medium for rapid growth and bioassays with tobacco tissue cultures. Physiologia Plantarum, 15:473-497.

Savitci LA, Gasparino Filho J, Leite RSSF \& Blinska FMM (1996) Packing house e mercado para o abacaxi. Boletim do Centro de Pesquisa de Processamento de Alimentos, 14:181-202.

Silva AB (2006) Biorreator e luz natural na micropropagação de abacaxizeiro. Tese de Doutorado. Universidade Federal de Lavras, Lavras. 132p.

Silva AB, Pasqual M, Castro EM, Miyata LY, Melo LA \& Braga FT (2008) Luz natural na micropropagação do abacaxizeiro (Ananas comosus L. Merr). Interciência, 33:839-843.

Souza-Júnior EE, Barboza SBSC \& Souza LAC (2001) Efeitos de substratos e recipientes na aclimatização de plântulas de abacaxizeiro (Ananas comosus L. Merr) cv. Pérola. Pesquisa Agropecuária Tropical, 31:147-151.

Spironello A (2010) Abacaxi. In: Donadio LC (Ed.) História da fruticultura paulista. Jaboticabal, Maria de Lourdes Brandel-ME. p.61-82.

Rev. Ceres, Viçosa, v. 59, n.5, p. 580-586, set/out, 2012 